\title{
ÉTUDE SÉRO-ÉPIDÉMIOLOGIQUE DE LA COWDRIOSE CHEZ LE ZÉBU MAURE AU SÉNÉGAL
}

\author{
MBENGUE M.*, GUEYE A.*, FAYE O.**, TOGUEBAYE B.S.*** KONTE M.*
}

Summary: SERO-EPIDEMIOLOGICAL STUDY AGAINST COWDRIOSIS FOR MAURE ZEBU CATTLE FROM DIFFERENTS AFRICAN AREAS

The seroprevalence against heartwater for maure zebus coming from Mali and Mauritania is analysed by indirect ELISA using the major antigenic protein $n^{\circ}$ 1-B (MAP1-B). Sero-epidemiological results realized on maure zebu cattle give a good adequation between the abundance or absence of the vector tick in the two countries for $98 \%$ of prevalence in Mali (infected area) and $0 \%$ of prevalence in Mauritania (non infected area).

KEY WORDS : cowdriosis, ELISA, epidemiology, maure zebu, Amblyomma variegatum, Senegal, Mali, Mauritania.

\footnotetext{
L
} a cowdriose, bactériose due à Ebrlichia ruminantium, constitue l'une des plus redoutables maladies transmises par les tiques au bétail sous les tropiques. L'agent causal a été identifié par Cowdry en 1925. Cette maladie infectieuse africaine, inoculable et non contagieuse, a été introduite aux Antilles pour la première fois au début du $18^{\text {ème }}$ siècle (Maillard \& Maillard, 1988) lors de l'importation de bétail africain porteur de la tique vectrice Amblyomma variegatum (Fabricius, 1794), selon Curasson (1941). La cowdriose se révèle plus que jamais être une maladie d'actualité et demeure une contrainte majeure dans beaucoup de systèmes d'élevage, particulièrement ceux à caractère intensif.

Dans le but d'améliorer le niveau de la production laitière au Sénégal, on assiste depuis quelques années à une introduction de plus en plus importante du zébu maure dans la région des Niayes, zone d'enzootie de cowdriose (Gueye et al., 1982). Cet animal, de bonne capacité laitière, semble s'y adapter contrairement à d'autres races exotiques. Son comportement vis-à-vis de la cowdriose présente un grand intérêt économique qui justifie les recherches menées sur cette race en vue de sa plus grande exploitation dans les troupeaux villageois.

\footnotetext{
* Institut sénégalais de recherches agricoles, Laboratoire national de l'élevage et de recherches vétérinaires, BP 2057, Dakar Hann, Sénégal.

** Université Cheikh Anta Diop, Département de Biologie animale de la Faculté des sciences et techniques, Dakar, Sénégal.

Correspondance : Mbaye Mbengue. E-mail : mbenguem@yahoo.fr
}

\section{Résumé :}

La séroprévalence de la cowdriose chez des zébus maures en provenance du Mali et de Mauritanie a été analysée par la technique de l'ELISA indirect utilisant la protéine antigénique majeure $n^{\circ}$ 7-B (MAPT-B). Les résultats de l'étude séroépidémiologique réalisée chez ces zébus montrent une bonne adéquation entre la prévalence, d'une part, et l'abondance ou l'absence de la tique vectrice, d'autre part, dans les deux pays d'origine avec un taux de $98 \%$ au Mali (zone infectée) et de $0 \%$ en Mauritanie (zone indemne).

MOTS CLÉS : cowdriose, ElISA, épidémiologie, zébu maure, Amblyomma variegatum, Sénégal, Mali, Mauritanie.
Afin de mieux appréhender la capacité de ces animaux à supporter cette rickettsiose dans les conditions de l'élevage traditionnel, l'étude de séroprévalence dans divers contextes épidémiologiques a été entreprise. L'étude sérologique par la technique ELISA indirecte pouvant permettre d'apprécier l'importance des contacts entre l'agent infectieux et ses hôtes bovins a été réalisée.

\section{MATÉRIELS ET MÉTHODES}

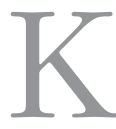
it utilisé (non commercial) - Antigène MAP1

L'antigène Ehrlichia ruminantium (Major antigenic protein-MAP) a été obtenu par culture sur cellules endothéliales bovines (Mahan et al., 1998). Le gène codant pour cette protéine MAP1-B a été cloné après amplification par PCR à partir d'Escherichia coli (Van Vliet et al., 1995; Martinez et al., 1990; Rousselot, 1953). Il s'agit d'une protéine recombinante, purifiée par chromatographie en phase liquide sur colonne échangeur anionique (chromatographie d'affinité) à partir du lysat d'Escherichia coli contenant le plasmide codant pour l'antigène MAP1-B. L'antigène préparé, de concentration $0,5 \mu \mathrm{g} / \mathrm{ml}$, est aliquoté par $1 \mathrm{ml}$ au titre de $1 / 1000$ et conservé à $-20^{\circ} \mathrm{C}$.

- Conjugué

Le sérum anti $\operatorname{IgG}$ de bovin est marqué à la peroxydase (kit ELISA non commercial contenant l'antigène 
Cowdria recombinant MAP1-B), titré et utilisé à la dilution au 1/2000.

- Substrat

Il s'agit d'une solution de tetra-methyl-benzydine (TMB) en mélange à parties égales avec de l'eau oxygénée à $30 \%$, qui est utilisée comme révélateur de l'enzyme du conjugué.

- Échantillons

Ils sont constitués de sérums témoins de référence positifs et négatifs fournis par le kit et dilués au 1/200, et de sérums de bovins zébu maure utilisés à la même dilution.

\section{Animaux d'expériences}

Ce sont des bovins zébus maures en provenance du Mali et de la Mauritanie et stationnés aux abattoirs de Dakar. Le zébu maure est un zébu à courtes cornes, de type maure, élevé selon le mode extensif, qui s'est bien développé en Mauritanie et qui est désigné sous l'appellation de zébu arabe, zébu mauritanien ou zébu gabarouyé. Cet animal est aussi présent au Mali. À l'âge de huit à 12 ans, il présente un développement musculaire considérable, avec un poids vif moyen de $340 \mathrm{~kg}$ et un rendement avoisinant les $50 \%$ (Doutressoulle et Traoré, 1949). Le taureau maure est lent à la saillie (Joshi et al., 1957).

Méthode d'étude séro-épidémiologique

L'étude de la séroprévalence de la cowdriose à été effectuée chez les bovins zébus maures aux abattoirs de Dakar : 200 zébus, dont 134 en provenance de la Mauritanie et 66 en provenance du Mali, ont fait l'objet de prélèvements sanguins aux abattoirs durant la période allant d'août à octobre 1997. Les récoltes ont été faites à l'aide de tubes vacutainers non héparinés de $10 \mathrm{ml}$, au niveau de la veine jugulaire, dans la minute qui a suivi l'abattage. Les prélèvements ont été centrifugés à 3000 tours par minute pendant 15 minutes, et les sérums recueillis aliquotés dans des tubes individuels en plastique de $2 \mathrm{ml}$. Ils ont ensuite été marqués et conservés à $-20^{\circ} \mathrm{C}$ jusqu'au moment du test ELISA indirecte selon la procédure courante. Le seuil de positivité moyen pour ce test est de 60 \%. Les sérums de référence (négatif et positif) du kit ELISA non commercial ont été reconstitués avec de l'eau distillée et aliquotés en $5 \mu \mathrm{l}$ et stockés à $-20^{\circ} \mathrm{C}$ et dilués au 1/200 pour le test.

\section{RÉSULTATS}

- es résultats sont rapportés dans le tableau I et la figure 1.

1 On note une prévalence très élevée de l'infection chez les zébus maures en provenance du Mali, avec un taux de $98 \%$ sur l'échantillonnage analysé. Ces bovins ne présentent cependant aucun symptôme par-

\begin{tabular}{lccc}
\hline \multicolumn{1}{c}{ Pays } & $\begin{array}{c}\text { Sérums } \\
\text { analysés } \\
\text { (N) }\end{array}$ & $\begin{array}{c}\text { Sérums } \\
\text { positifs } \\
\text { (N) }\end{array}$ & $\begin{array}{c}\text { Prévalence } \\
\text { (\%) }\end{array}$ \\
\hline Mauritanie & 134 & 0 & 0 \\
Mali & 66 & 65 & 98 \\
\hline
\end{tabular}

Tableau I. - Taux de séroprévalence de la cowdriose chez le zébu maure aux abattoirs de Dakar.

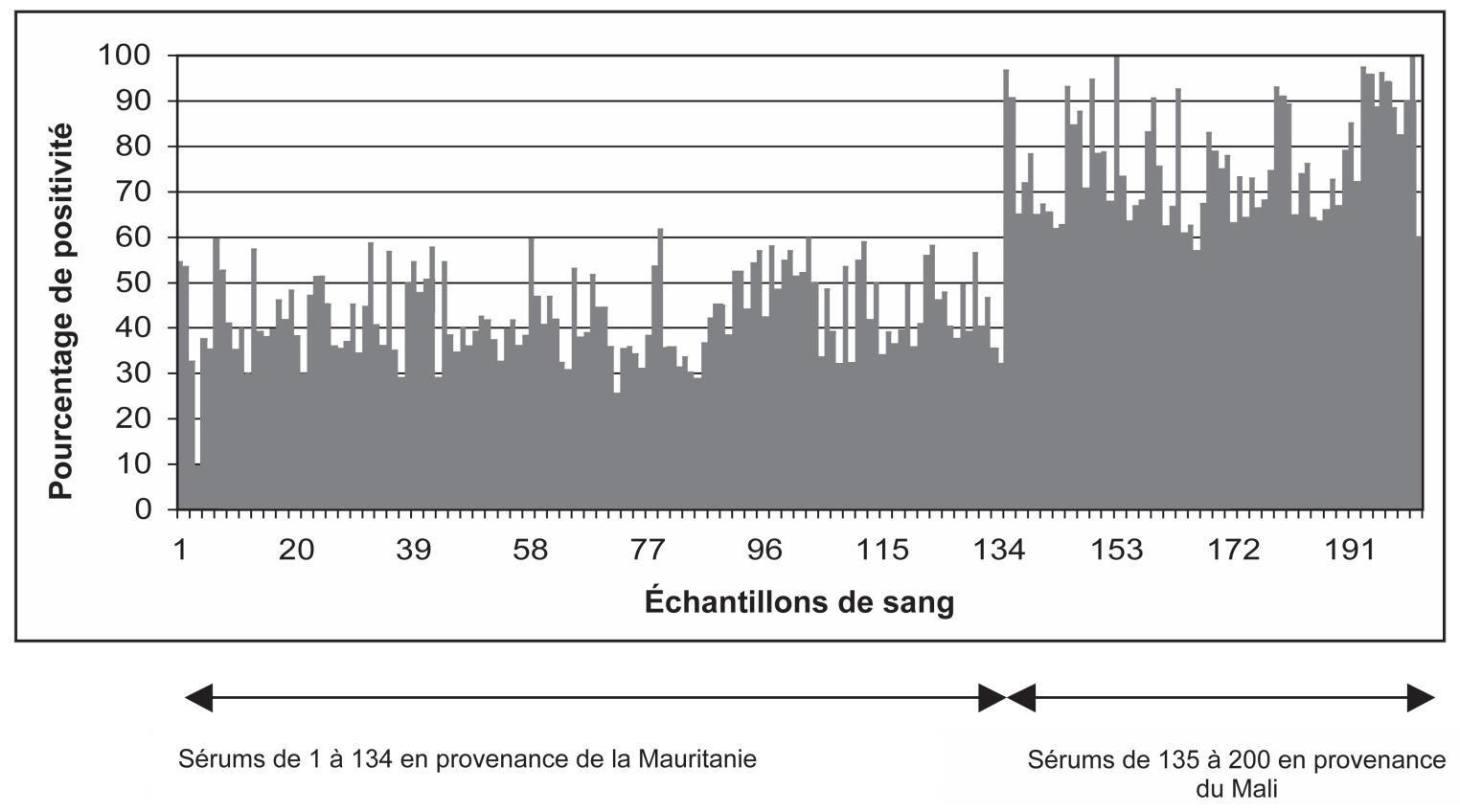

Fig. 1. - Séropositivité (\%) des zébus maures selon leur provenance géographique. 
ticulier, contrairement aux petits ruminants du Mali chez lesquels des mortalités et autres signes cliniques sont rapportés par divers auteurs (Rousselot, 1953) alors que la distribution d'Amblyomma variegatum, vecteur de l'agent infectieux, intéresse une bonne partie du territoire. En Mauritanie, l'infection est par contre inexistante; la valeur nulle de la prévalence de l'infection chez le zébu corrobore la rareté ou l'absence de la tique vectrice dans ce pays.

\section{CONCLUSIONS}

- 'utilisation de la protéine antigénique majeure MAP1-B d'Ehrlichia ruminantium en ELISA indi$\checkmark$ rect nous a permis d'apprécier le taux de prévalence de zébus maures dans différents contextes épidémiologiques, et pourrait confirmer l'existence de contacts infectants entre ces bovins et la rickettsie en zone d'enzootie où l'on note une abondance du vecteur (Gueye et al., 1993).

\section{RÉFÉRENCES}

Curasson G. La rickettsiose générale ovine au Sénégal (première note) : la maladie expérimentale. Bulletin des Services Zootechniques et des Épizooties de l'AOF, 1941, Fascicule 1, 34-36.

Doutressoulle G. \& Traoré S. L'élevage dans la boucle du Niger. Revue de d'Élevage et de Médecine Vétérinaire des Pays Tropicaux, 1949, 3, 17-28.

Gueye A., Mbengue M, Kebe B \& Diouf A. Note épizootiologique sur la cowdriose bovine dans les Niayes au Sénégal. Revue d'Élevage et de Médecine Vétérinaire des Pays Tropicaux, 1982, 35, 217-219.

Gueye A., Mbengue M. \& Diouf A. Épidémiologie de la cowdriose au Sénégal. I. Étude de la transmission et du taux d'infection d'Amblyomma variegatum (Fabricius, 1794) dans la région des Niayes. Revue d'Élevage et de Médecine Vétérinaire des Pays Tropicaux, 1993, 46, 441-447.

Joshi N.R., Laughuin E.A. \& Phillips R W. Les bovins d'Afrique : types et races. Études Agricoles n 37. Rome: FAO, 1957.

MAHAN et al. Evaluation of the MAP1-B ELISA for cowdriosis with field sera from livestock in Zimbabwe. Annales of New York Academy of Sciences, 1998, 849, 259-261

MaILlaRD J.C et al. Historique du peuplement bovin et de l'introduction de la tique Amblyomma variegatum dans les îles françaises des Antilles : synthèses bibliographiques. Ethnozootechnie, Varia, 1988, 61, 19-35.

Martinez D., Swinkels J., Camus E \& Jongejan F. Comparaison de trois antigènes pour le sérodiagnostic de la cowdriose par immunofluorescence indirecte. Revue d'Élevage et de Médecine Vétérinaire des Pays Tropicaux, 1990, 43, 159166.

Rousselot R. Notes de parasitologie tropicale. Tome 1. Paris : Vigot et frères, 1953.
Van Vliet. A.H., Van Der Zeijst B.A., Bernard A.M., Camus E., Mahan S, Martinez D. \& Jongejan F. Use of a specific immunogenic region on the Cowdria ruminantium MAP1 protein in a serologycal assay. Journal of Clinical Microbiology, 1995, 33 (09), 2405-2410.

Reçu le 19 juin 2006 Accepté le 23 février 2007 